\title{
Article
}

\section{Variation of radiofrequency intensities from the DTTV-transmitter in Kampala Metropolitan; Uganda}

\author{
Peter Opio $^{1, *}$, Akisophel Kisolo ${ }^{1}$, Willy Okullo ${ }^{1}$ and Tumps. W. Ireeta ${ }^{1}$ \\ 1 Department of Physics, College of Natural Science, Makerere University, P.O Box 7062, Kampala, Uganda. \\ * Correspondence: opiop@cns.mak.ac.ug
}

Received: 1 September 2020; Accepted: 24 January 2021; Published: 29 January 2021.

\begin{abstract}
This paper presents the variation of radiofrequencies intensities from the DTTV-transmitter in Kampala Metropolitan for the sub $700 \mathrm{MHz}(470-694 \mathrm{MHz})$ and the $700 \mathrm{MHz}(694-790 \mathrm{MHz})$ frequency bands. The results of this study showed that though all the measurement locations from the transmitter have a good reception of DTTV signals, their radiofrequency intensities varied at the different points on the same measurement location at a constant distance from the DTTV transmitter. The study further showed that there is a general decrease in the radiofrequency intensities for the sub $700 \mathrm{MHz}$ frequency band and a slight general increase in the radiofrequency intensities for the $700 \mathrm{MHz}$ frequency band. This research revealed that the measured Reference Signal Received Power (RSRP) values for all the measurement locations where within the IEEE and FCC recommended values for any DTTV signal reception.
\end{abstract}

Keywords: Frequency band, radiofrequency intensities, DTTV-transmitter, Reference Signal Received Power (RSRP).

\section{Introduction}

$\mathbf{T}$ ransmission of television signals ever since the inception of television broadcast [1] has been on the Analogue Television (ATV) technology until a couple of years ago that Digital Terrestrial Television (DTTV) technology was proposed in a bid to maximize frequency spectrum and have good quality of television services [2]. With DTTV technology, television signals are transmitted by multiplex transmitters (transmission of many channels in a single frequency range) and are being radiated from the transmitting antenna whereas in ATV technology, the signals are transmitted through a single channel by an analogue transmitter [3]. Reception of DTTV signals is always influenced by a number of factors like; the height of transmitting and receiving antenna's, the output power of the transmitter [4], the terrain between the transmitter and the receiver, the effect of meteorological parameters [5] and foliage, amongst others.

All forms of radiation in free space are governed by the inverse square law. For this law, if the distance from the transmitter is doubled, the power density of the radiated wave is reduced to a quarter of its former value at the new location. Power density is the radiated power per unit area, hence a measure of radiofrequency intensity and received signal strength. In radiation, power density is directly proportional to the transmitted power and is inversely proportional to the square of the distance from the source [6-8]. Therefore;

$$
\begin{aligned}
\mathfrak{p}_{d} & \propto \frac{\mathfrak{p}_{t}}{r^{2}}, \\
\mathfrak{p}_{d} & =\frac{\mathfrak{p}_{t}}{4 \pi r^{2}},
\end{aligned}
$$

where, $\mathfrak{p}_{d}$ is the power density at a distance $r(m)$ from the transmitter and $\mathfrak{p}_{t}$ is the transmitted power, all the powers measured in watts.

Globally, almost all countries have switched onto DTTV in accordance with the dates of 17 June 2015 (for Ultra High Frequency) and 17 June 2020 (for Very High Frequency) as set by ITU [9] for its member states, including Uganda. 
Uganda being in ITU region 1, her DTTV broadcasting service has a primary allocation of $470-790 \mathrm{MHz}$ frequency band and the Digital Switch Over (DSO) was done on June 2015, within $60 \mathrm{Km}$ radius of Kampala Metropolitan [10].

The motivation for this research was because Kampala Metropolitan, Uganda, was the first region to undergo full DSO and as a result, there was need to know the quality of service, the propagation pattern and coverage of DTTV signals with distance from the transmitter at various climatic zones.

Radiofrequency intensity is a measure of the DTTV received signal (received power). The higher the value of RF intensity, the higher is the received power from the DTTV transmitter and the better is the quality of the received TV signal. The purpose of this work is to study the variation of radiofrequency intensity for different distances from the transmitter. Related studies by different researchers from different countries (Nigeria, Korea, India, and Spain) have been carried out as explained by [11-14]. In these studies, the quality of DTTV signals reception at different distances and locations have been analyzed.

In Uganda, since little is known about radiofrequency intensities from DTTV transmitter and their relation to TV signals reception, this study is important in order to give a clear sense about the DTTV situation. With this study, we will be able to know the signal attenuation in DTTV transmission. In ATV technology, signal attenuation may not lead into total loss of the signal, which is not the case with DTTV technology. In DTTV technology, TV reception levels below $-116 \mathrm{dBm}$, will lead to total loss of signals $[13,15,16]$.

\section{Materials and methods}

In order to investigate the variation of radiofrequency intensities from the broadcasting transmitter in Kampala, measurements were done in an outdoor setting for a period of two months. The measurements first considered all the DTTV- UHF frequency band of $470-862 \mathrm{MHz}$ and there after a $470-790 \mathrm{MHz}$ frequency band as assigned to Uganda by the ITU [9] and as implemented by UCC [10] was selected.

\subsection{Measurement location}

The two month measurements were conducted during day hours at seven different locations which were marked on different eight concentric circles, that's, CC1, CC2, CC3, CC4, CC5, CC6, CC7 and CC8. The radius of these concentric circles determined the horizontal distances between the measured points, that's receiver antenna and the transmitter. The radii of CC1, CC2, CC3, CC4, CC5, CC6, CC7 and CC8 were; $1 \mathrm{Km}, 2 \mathrm{Km}$, $3 \mathrm{Km}, 4 \mathrm{Km}, 5 \mathrm{Km}, 6 \mathrm{Km}, 7 \mathrm{Km}$ and $8 \mathrm{Km}$ respectively, from the transmitter. A Google map of one of the measurement location at Latitude: 0.348340, Longitude: 32.599286 is shown in Figure 1.

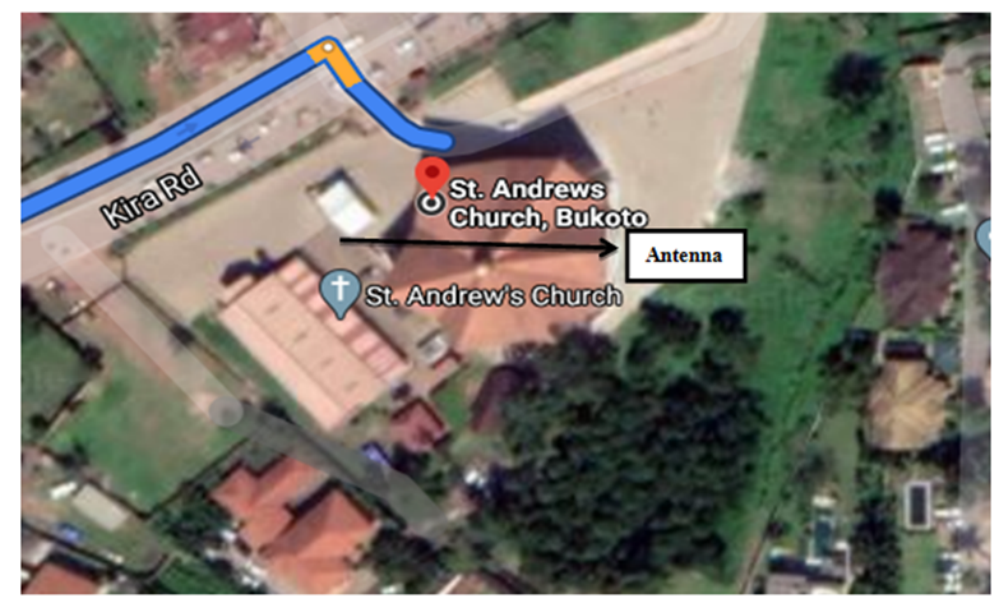

Figure 1. One of the measurement locations

Each measurement location chosen in this research had at least the minimum achievable Direct Line of-Sight (DLoS) with the DTTV-Transmitter and the minimum distance of the receiving antenna from the ground. The locations are in urban setting hence allowing signal measurements which have encountered less distortion in form of; absorption, diffraction, reflection, refraction, scattering and directional characteristics of both the transmitter and the receiver antennas [17]. 


\subsection{Measurement setup}

The Setup measurement at every measurement location was made up of a calibrated Aaronia Spectran HF-6065V4 spectrum analyzer, an Aaronia AG HyperLOG 4025 Antenna, a T430s Lenovo Laptop, connected to the spectrum analyzer via a USB cable, and the MCS software. The MSC software is specifically designed to run on Aaronia spectrum analyzers and can easily suit a given measurement since it is easy to configure. Points on each concentric circle as shown in Figure 2, where randomly selected and determined the Measurement Locations (MLos).

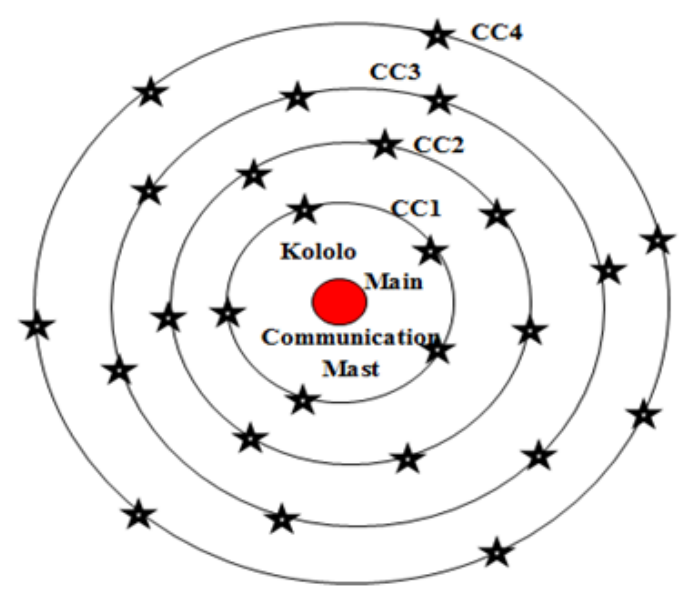

Figure 2. View of the Measurement Locations (MLos) on the concentric circles

A full over view of the UHF frequency band of 470-862 MHz at different seven location measurements were taken. An average of two times measurements at every measurement location were taken for every 5 minutes for a period of 10 minutes before taking the actual average measurements of the frequency band variation of radiofrequency intensities. The radiofrequency intensity measurements were measured in form of Reference Signal Received Power (RSRP).

In Kampala Uganda, the DVB-Transmitter broadcasts all the television signals within the frequency range of $470-790 \mathrm{MHz}$, with the $(470-694) \mathrm{MHz}$ as the sub $700 \mathrm{MHz}$ frequency band and $(694-790) \mathrm{MHz}$ as the $700 \mathrm{MHz}$ frequency band.

The configurations of the parameters for the spectrum analyzer on the MCS software during the measurements are as in Table 1.

Table 1. Parameter configuration for the spectrum analyzer

\begin{tabular}{c|c}
\hline Parameter & Value \\
\hline UHF Frequency range & $470 \mathrm{MHz}-862 \mathrm{MHz}$ \\
\hline DVB-T broadcasting band & Sub 700 MHz band \\
\hline & $700 \mathrm{MHz}$ band \\
\hline Resolution Band Width & $100 \mathrm{KHz}$ \\
\hline Video Band Width & $100 \mathrm{KHz}$ \\
\hline Sweep time & $5 \mathrm{~ms}$ \\
\hline Detection type & RMS \\
\hline Sample points & 100 \\
\hline Attenuation factor & Auto \\
\hline Reference level & -10 \\
\hline Unit & $\mathrm{dBm}$
\end{tabular}

\section{Results and discussion}

Measurements of all the UHF frequency range for DTTV has been made for the eight concentric circles whose GPS coordinates for every measurement locations on each circle are as seen in Table 2. 
Table 2. GPS coordinates for the different measurements location on the different concentric circles

\begin{tabular}{|c|c|c|c|c|c|c|c|c|c|}
\hline $\begin{array}{l}\text { Measurement } \\
\text { Location } \\
\text { (MLo) }\end{array}$ & $\begin{array}{c}\text { GPS } \\
\text { Coordinates }\end{array}$ & CC1 & $\mathrm{CC} 2$ & CC3 & CC4 & CC5 & CC6 & CC7 & $\mathrm{CC} 8$ \\
\hline \multirow[t]{3}{*}{1} & Latitude & 0.333206 & 0.3289499999 & 0.32991 & 0.3259216666 & 0.34824833 & 0.3294266 & 0.33092667 & 0.268925 \\
\hline & Longitude & 32.587644 & 32.583011667 & 32.573885 & 32.56545466 & 32.56278166 & 32.55229 & 32.54564167 & 32.56618 \\
\hline & Altitude & 1203 & 1175 & 1201 & 1188 & 1173 & 1242 & 1271 & 1169 \\
\hline \multirow[t]{3}{*}{2} & Latitude & 03272016 & 0.31827 & 0.338485 & 0318931666 & 0.3355267 & 0.33825 & 0.294815 & 00.2728 \\
\hline & Longitude & 32.596766 & 32.590304999 & 32.5741 & 32.57049833 & 32.5610267 & 32.55502 & 32.55228 & 32.6175 \\
\hline & Altitude & 1212 & 1172 & 1187 & 1165 & 1194 & 1213 & 1192 & 1159 \\
\hline \multirow{2}{*}{3} & Longitude & 32.593256 & 32.60148 & 32.5564 & 32.615865 & 32.5564 & 32.603058 & 32.561648 & 32.6634 \\
\hline & Altitude & 1215 & 1178 & 1206 & 1163 & 1206 & 1198 & 1195 & 1178 \\
\hline \multirow[t]{3}{*}{4} & Latitude & 0.336998 & 0.3407016666 & 0.338033 & 0.34417333 & 0.3320315 & 0.5666 & 0.367295 & 0.3802 \\
\hline & Longitude & 32.857303 & 32.58882333 & 32.6052317 & 32.61251 & 32.6201275 & 32.61553 & 32.559543 & 32.5571 \\
\hline & Altitude & 1222 & 1220 & 1182 & 1196 & 1176 & 1226 & 1194 & 1221 \\
\hline \multirow[t]{3}{*}{5} & Latitude & 0.33781 & 0.337476666 & 0.326389 & 0.348340 & 0.3485786 & 0.312345 & 0.362268 & 0.3653 \\
\hline & Longitude & 32.67239 & 32.58385 & 32.577222 & 32.599286 & 32.6197121 & 32.636113 & 32.62246 & 32.6249 \\
\hline & Altitude & 1167 & 1212 & 1236 & 1229 & 1195 & 1164 & 1198 & 1220 \\
\hline \multirow{2}{*}{6} & Longitude & 32.587303 & 32.582681666 & 32.5856083 & 32599863 & 32.608873 & 32.56648 & 32.6368 & 32.84564 \\
\hline & Altitude & 1202 & 1207 & 1185 & 1200 & 1230 & 1195 & 1194 & 32.8451155 \\
\hline \multirow[t]{3}{*}{7} & Latitude & 0.33702833 & 0.3218983333 & 0.32368 & 0.334916 & 0.3626862 & 0.302166 & 0.304356 & 0.2954 \\
\hline & longitude & 32.5896266 & 32.60433833 & 3257712 & 32.566301 & 32.6014431 & 32.552638 & 32.643552 & 32.5424 \\
\hline & Altitude & 1255 & 1162 & 1181 & 1249 & 1197 & 1261 & 1162 & 1164 \\
\hline
\end{tabular}


In general, as seen in Figure 3, experimental results show that all Measurement Locations (MLo) on the different distances from the transmitter have a good reception of digital television signals.

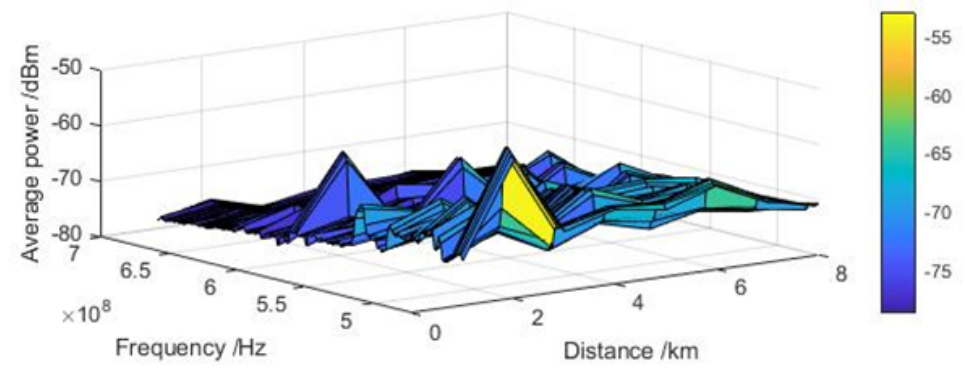

(a)

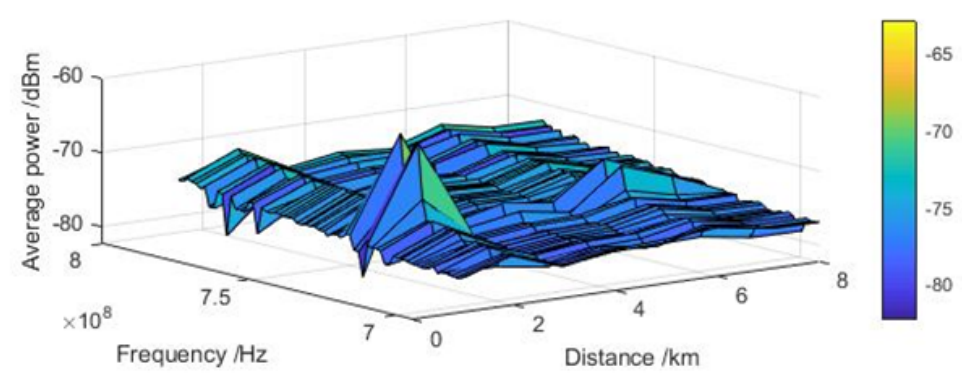

(b)

Figure 3. Radiofrequency intensity at different measurement locations for the different distances: The frequency ranges are $470 \mathrm{MHz}-694 \mathrm{MHz}$ for (a) and $694 \mathrm{MHz}-790 \mathrm{MHz}$ for (b)

Theoretically, radiofrequency intensities at a constant distance from the broadcasting transmitter must be constant. However, this is not the case as seen in Figures 3-7 since the graphs obtained show that radiofrequency intensities vary with location for the same distance though measurements were taken at the least possible DLoS with the transmitter at every measurement location. This means that in some locations there are more obstacles yielding to low radiofrequency intensities while in some there a few obstacles leading to high values of radiofrequency intensities. This cause may also be due to multipath effects giving graphs of varying radiofrequency intensities

This same trend was also observed on the different MLos of the; $2 \mathrm{~km}, 4 \mathrm{~km}, 6 \mathrm{~km}$ and the $8 \mathrm{~km}$ distances. From Table 2, every concentric circle has different altitudes for the different Measurement locations indicating that some MLos are in the valley while as others are on the hill; hence differences in RF Intensities for the same CC.

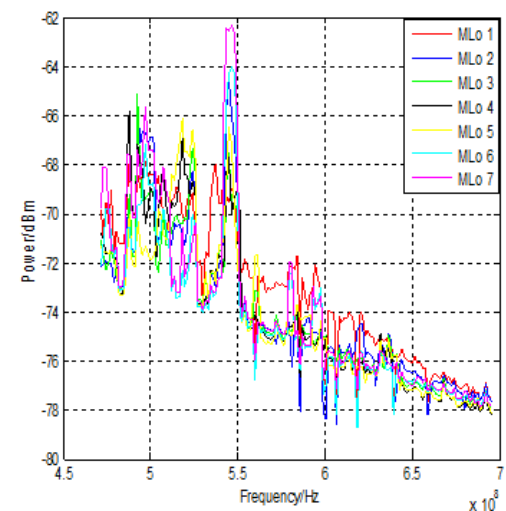

(a)

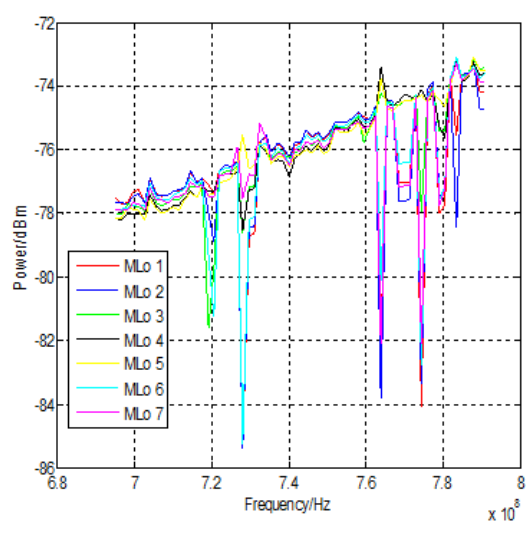

(b)

Figure 4. Radiofrequency intensities at various measurement locations for the $3 \mathrm{~km}$ distance from the transmitter. The frequency ranges are $470 \mathrm{MHz}-694 \mathrm{MHz}$ for (a) and $694 \mathrm{MHz}-790 \mathrm{MHz}$ for (b) 


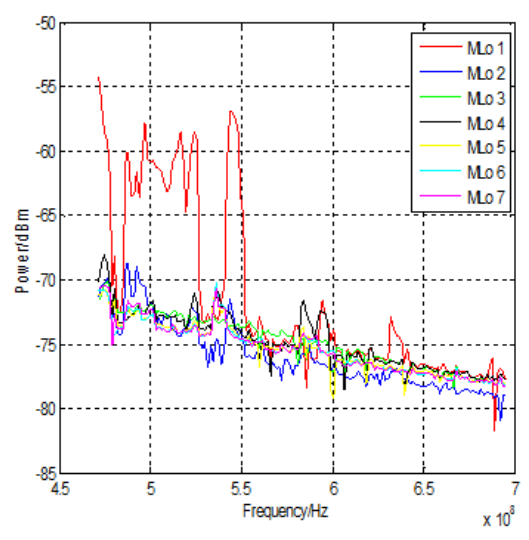

(a)

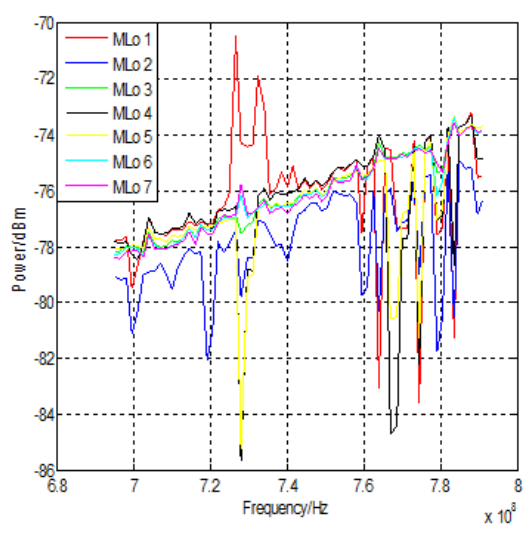

(b)

Figure 5. Radiofrequency intensities at various measurement locations for the $3 \mathrm{~km}$ distance from the transmitter. The frequency ranges are $470 \mathrm{MHz}-694 \mathrm{MHz}$ for (a) and $694 \mathrm{MHz}-790 \mathrm{MHz}$ for (b)

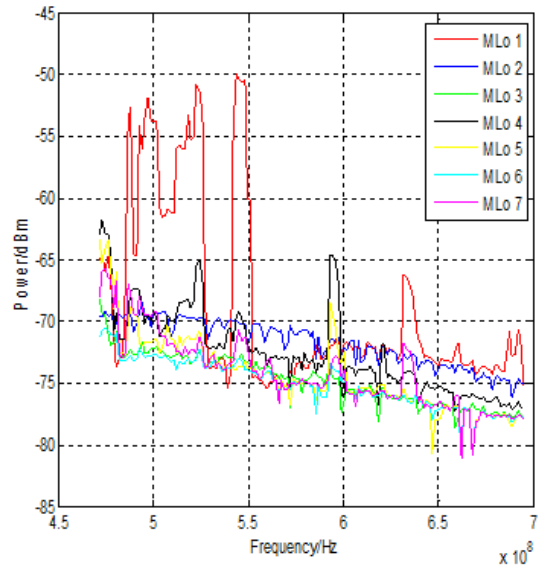

(a)

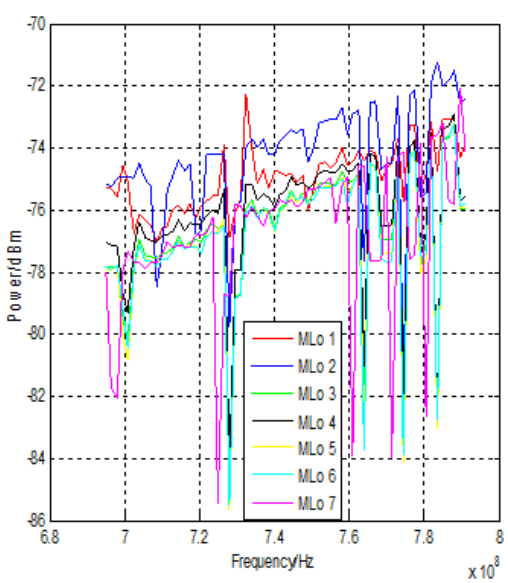

(b)

Figure 6. Radiofrequency intensities at various measurement locations for the $5 \mathrm{~km}$ distance from the transmitter. The frequency ranges are $470 \mathrm{MHz}-694 \mathrm{MHz}$ for (a) and $694 \mathrm{MHz}-790 \mathrm{MHz}$ for (b)

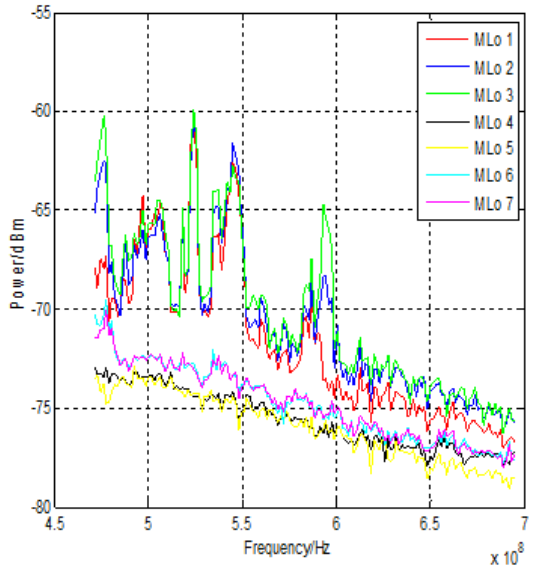

(a)

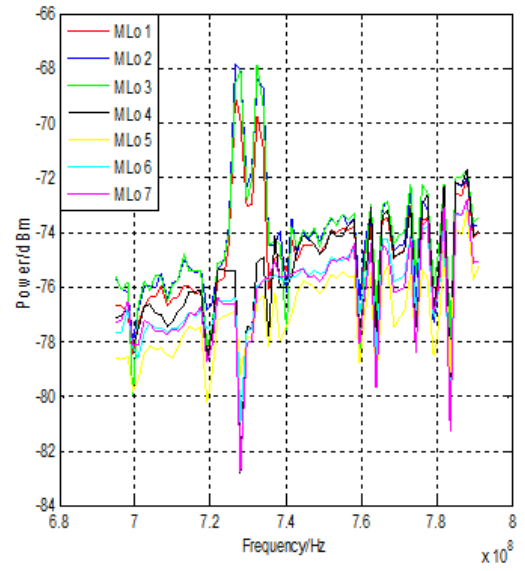

(b)

Figure 7. Radiofrequency intensities at various measurement locations for the $7 \mathrm{~km}$ distance from the transmitter. The frequency ranges are $470 \mathrm{MHz}-694 \mathrm{MHz}$ for (a) and $694 \mathrm{MHz}-790 \mathrm{MHz}$ for (b) 
Another observation made here is that there is a general decrease in the radiofrequency intensities with increasing frequency for the $470 \mathrm{MHz}-694 \mathrm{MHz}$ frequency band while as for the $694 \mathrm{MHz}-790 \mathrm{MHz}$ frequency band, there is a slight general increase in the radiofrequency intensities as the frequency increases, for every measurement location of every frequency value. This also means that more TV stations are located within the sub $700 \mathrm{MHz}$ frequency band than in the $700 \mathrm{MHz}$ frequency band.

When a single frequency value of $542 \mathrm{MHz}$ from the sub $700 \mathrm{MHz}$ frequency band was considered, for each distance with its MLos as seen in Figures 8 below, the RF intensity for every MLo for a particular concentric distance from the transmitter is not constant [18]. This is because different MLos on the same concentric circle had different altitudes, hence giving different values of RF intensities on the same concentric circle. Specifically, MLos on CC2, CC4 and CC6, recorded higher values than those ones on CC1, CC3 and CC5, yet $\mathrm{CC} 1, \mathrm{CC} 3$ and $\mathrm{CC} 5$ are closer to the transmitter than $\mathrm{CC} 2, \mathrm{CC} 3$ and $\mathrm{CC} 6$, respectively. This same difference was also observed on the $740 \mathrm{MHz}$ frequency selected from the $700 \mathrm{MH}$ frequency band. These observations do not conform to the inverse square law and the mathematical expression as shown in Equation (1)

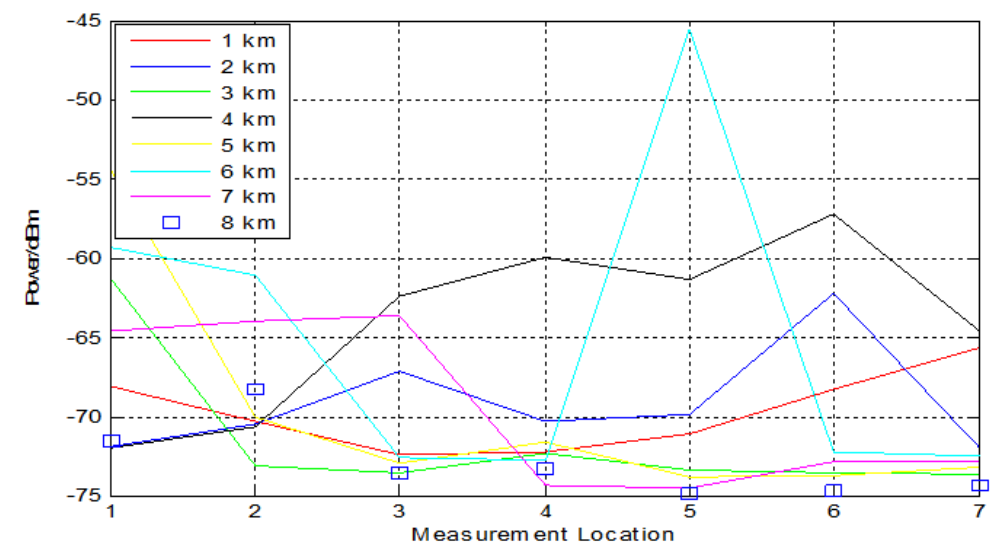

Figure 8. Radiofrequency intensities at various measurement locations of different distances from the transmitter for the $542 \mathrm{MHz}$ frequency taken from the sub $700 \mathrm{MHz}$ frequency band

From Figure 9, it is noted that there is total non-observance of the inverse square law. In (a), it is expected that RF intensities at all MLos on the $1 \mathrm{~km}$ distance would be greater than the rest of the RF intensities for all other distances, but it was not so. This also applies in (b) for the $2 \mathrm{~km} \mathrm{RF}$ intensities at all the MLos on the $2 \mathrm{~km}$ in comparison to other distances from the transmitter [4]. The same was observed for the $740 \mathrm{MHz}$ frequency selected from the $700 \mathrm{MHz}$ frequency band.

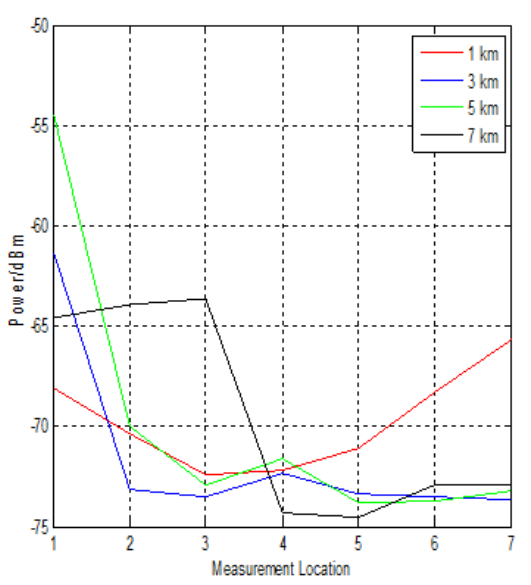

(a)

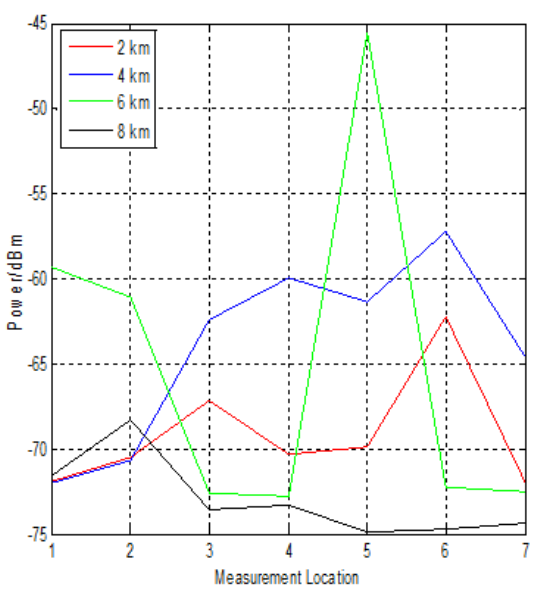

(b)

Figure 9. Radiofrequency intensities at various measurement locations of different distances from the transmitter for the $542 \mathrm{MHz}$ frequency taken from the sub $700 \mathrm{MHz}$ frequency band. The distances are odd for (a) and even for (b) 


\section{Conclusion}

In this paper, radiofrequency intensities from the Digital Terrestrial Television (DTTV) Broadcasting Transmitter in Kampala Metropolitan have been measured and analyzed. The measurements generally show that there is a variation of radiofrequency intensities for a constant distance from the DVB-T Transmitter for any point around it. The measurements have shown that the sub $700 \mathrm{MHz}$ frequency band of $470 \mathrm{MHz}-694 \mathrm{MHz}$ is more utilized than the $700 \mathrm{MHz}$ frequency band of $694 \mathrm{MHz}-790 \mathrm{MHz}$; though both bands are still less utilized as being expected by ITU and UCC. The study has also revealed that in Kampala Metropolitan, there is good reception of DTTV signals at all the Measurement Locations where DTTV RF intensities measurements where carried from. The measurements do not obey the inverse square law which governs all forms of radiation in free space. This is evidenced on comparison of the RF Intensity measurements of CC1 with CC2, CC3 with CC4, CC5 with CC6 and CC7 with CC8. This is due to different Measurement Locations on the same CC having different altitude values. The study has come at the rightful time when there is an increase in the number of DVB-television stations in Kampala Metropolitan, Uganda.

Acknowledgments: The authors are indebted to Dr. Akisophel Kisolo for providing the transport means that were used while collecting the data from the different measurement locations and extend their thanks to Dr. Gertrude Ayugi for providing the Spectrum Analyzer that was used in this study.

Author Contributions: All authors contributed equally to the writing of this paper. All authors read and approved the final manuscript.

Conflicts of Interest: "The authors declare no conflict of interest."

\section{References}

[1] Whitaker, J. C. (2005). Standard Handbook of Broadcast Engineering. McGraw-Hill Education.

[2] Akinbolati, A., Ajewole, M. O., Adediji, A. T., \& Ojo, J. S. (2015). Determination and classification of coverage areas of terrestrial UHF television transmitters in Ondo state, Nigeria. International Organization of Scientific Research, Journal of Applied Physics (IOSR-JAP),7(4), 16-26.

[3] Murithi, K. K. M. (2001). IP Multicast in Digital Television Transmission Infrastructure, Doctoral dissertation. Massachusetts Institute of Technology, United States.

[4] Akinsanmi, A., Oludare, A. M., Titus, A. A., \& Sunday, O. J. (2017). The influences of meteorological parameters on digital terrestrial television (DTT) signal in the tropics. International Journal of Digital Information and Wireless Communications, 7(3), 161-173.

[5] Ajewole, M. O., Akinbolati, A., Adediji, A. T., \& Ojo, J. S. (2014). Precipitation effect on the coverage areas of terrestrial UHF television stations in Ondo state, Nigeria. International Journal of Engineering and Technology, 4(9), 524-535.

[6] Kerr, D. E., Goudsmit, S. A., \& Linford, L. B. (Eds.). (1987). Propagation of Short Radio Waves (Vol. 24). IET Digital Library.

[7] Kenedy, G., \& Bernard, D. (1992). Electronic communication system. In McGraw-Hill/Macmillan, Singapore (pp. 80-85).

[8] Akinbolati, A., Akinsanmi, O., \& Ekundayo, K. R. (2016). Signal strength variation and propagation profiles of UHF radio wave channel in Ondo state, Nigeria. International Journal of Microwave and Wireless Technologies, 6(4), $12-27$.

[9] Nagumo, S., \& Walker, D. A. (1989). Ocean bottom geoscience observatories: Reuse of transoceanic telecommunications cables. Eos, Transactions American Geophysical Union, 70(26), 673-677.

[10] Nyabuga, G., Booker, N., Dragomir, M., Thompson, M., Jamaï, A., Chan, Y. Y., \& Nissen, C. S. (2013). Mapping digital media: Kenya. Nairobi: Open Society Foundations.

[11] Akinbolati, A., Ikechiamaka, N. F., \& Akoma D. B. (2017). Variation of Digital Terrestrial Television Signal with Altitude in Akure, South West Nigeria. American Journal of Engineering Research, 6(12), 186-194.

[12] Assia Semmar., Jean-Yves Chouinard., Viet Ha Pham., Xianbin Wang, Yiyan Wu., \& Sébastien Laflèche. (2006). Digital Broadcasting Television Channel Measurements and Characterization for SIMO Mobile Reception. IEEE Transactions on Broadcasting, 52(4), 450-463.

[13] Armoogum, V. K. M. S., Soyjaudah, K. M. S., Mohamudally, N., \& Fogarty, T. (2010). Propagation models and their applications in digital television broadcast network design and implementation. In Book: Trends in Telecommunications Technologies, 165-183.

[14] Prasad, M. V. S. N. (2006). Path loss exponents deduced from VHF \& UHF measurements over Indian subcontinent and model comparison. IEEE Transactions on Broadcasting, 52(3), 290-298.

[15] Federal Communications Commission (FCC), Second report and order and memorandum. Opinion and order, Techical Report 08-260, November 2008. 
[16] IEEE 802.22 Working Group. (2008). IEEE P802. 22/D1. 0 draft standard for wireless regional area networks part 22: cognitive wireless RAN medium access control (MAC) and physical layer (PHY) specifications: policies and procedures for operation in the TV bands. IEEE docs, 22-06.

[17] Saunders, S. R., \& Aragi, A. (2007). Antennas and Propagation for Wireless Communication Systems. John Wiley \& Sons.

[18] Fogarty, T., Soyjaudah, K. M. S., \& Armoogum, V. T., \& Mohamudally, N.(2006). Signal strength variation measurements of digital television broadcasting for summer season in the north of Mauritius at UHF bands. In Proceedings of the 3rd International Conference on Computers and Device for Communication.

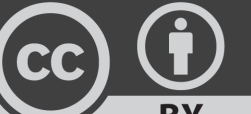

BY

(C) 2021 by the authors; licensee PSRP, Lahore, Pakistan. This article is an open access article distributed under the terms and conditions of the Creative Commons Attribution (CC-BY) license (http://creativecommons.org/licenses/by/4.0/). 